\title{
Trauma and Parenting Beliefs: Exploring the Ethnotheories and Socialization Goals of Palestinian Mothers
}

\author{
Saija L. Kankaanpää ${ }^{1,2} \cdot$ Sanna Isosävi $i^{2,3} \cdot$ Safwat Y. Diab ${ }^{2} \cdot$ Samir R. Qouta ${ }^{4} \cdot$ Raija-Leena Punamäki $\mathbb{C}^{2}$
}

Published online: 26 June 2020

(c) The Author(s) 2020

\begin{abstract}
Parenting beliefs are important to infant wellbeing, but there is a lack of research into their role in war conditions. We examined (1) how maternal traumatic experiences (war events and childhood abuse) and mental health would be associated with parenting beliefs about good childrearing practices (ethnotheories) and desirable child characteristics (socialization goals) and (2) whether parenting beliefs mediate the impact of traumatic experiences and mental health on mother-infant interaction and infant development. Palestinian mothers $(N=510)$ participated during pregnancy and at four and 12 months postpartum. They reported current traumatic war events, emotional and physical abuse in their own childhood and mental health (posttraumatic stress disorder, depression, and anxiety symptoms), their ethnotheories and socialization goals and the quality of dyadic mother-infant interactions and infant developmental skills (language, fine-motor, and gross-motor). High maternal exposure to traumatic war events was associated with higher autonomy-enhancing-and lower relatednessenhancing — socialization goals. Conversely, maternal childhood abuse was associated with higher relatedness-enhancingand lower autonomy-enhancing-socialization goals. High maternal exposure to traumatic war events was associated with high levels of positive dyadic interaction, whereas high emotional and physical abuse and mental health problems were associated with low levels of positive dyadic interaction. Parenting beliefs did not mediate the impact of maternal traumatic experiences and mental health on dyadic interaction or infant development. The nature of maternal traumatic experiences was central for the socialization goals in unique and specific ways. The findings emphasize the meaningfulness of parenting values, goals, and practices among mothers caring for their infants in war conditions.
\end{abstract}

Keywords Traumatic war events $\cdot$ Interpersonal trauma $\cdot$ Parenting beliefs $\cdot$ Mother-infant interaction $\cdot$ Infant development

\section{Highlights}

- The nature of maternal trauma is central to the preferred socialization goals.

- Traumatic war events enhance autonomy and childhood abuse relatedness.

- Prenatal mental health problems harmed mother-infant interaction, but left parental beliefs intact.

- Contextual and sociocultural factors need to be considered when studying parenting.

Raija-Leena Punamäki

raija-leena.punamaki-gitai@tuni.fi

1 Outpatient Clinic for Multicultural Psychiatry, Helsinki University Hospital, Helsinki, Finland

2 Department of Psychology, Faculty of Social Sciences, Tampere University, Tampere, Finland

3 Traumacentre Finland, Helsinki, Finland

4 School of Social Sciences and Humanities, Doha Institut for Graduate Studies, Doha, Qatar
Caregivers aim to provide the conditions for their children's optimal development, but the conceptualization of desirable rearing and development varies across sociocultural contexts. In order to thrive, parents and their children need to solve environment-specific developmental tasks and challenges. Parenting beliefs incorporate parenting ethnotheories about culturally salient and adaptive childrearing practices together with socialization goals about the salient human characteristics to be promoted in child development (Keller and Otto 2009; Super and Harkness 2002). The prenatal and postnatal periods are prime stages for the formation of parenting beliefs, and they are influenced both by 
mothers' own childhood histories and the current sociocultural context. Parenting beliefs subconsciously and consciously determine caregiving behavior and mother-infant interactions, which, together with maternal wellbeing, are central agents in child development and wellbeing (Keller 2007) and create the early human environment of infants (Stern 1998).

Parenting and infant development need to be considered in the physical, historical, and social context in which the families live. Societal emphasis on the two basic human needs of autonomy (i.e., individualism) and relatedness (i.e., collectivism) (Kagitcibasi 2005; Keller 2007) guide parents' and other caregivers' ideas about optimal caregiving and child development. Parents formulate ethnotheories that lineate appropriate caregiving practices in their given context, e.g., appropriate or adaptive ways to soothe a crying child or to arrange feeding or sleeping (Keller 2007). Distal strategies, which involve face-to-face communication, presenting infants with objects, and waiting for them to communicate (e.g., by crying) before responding, characterize autonomy-oriented caregiving. Proximal strategies, with emphasis on close bodily contact and anticipatory responses to infants' need expressions are, in turn, typical of relatedness-oriented caregiving. Socialization goals are another type of parenting belief, consisting of the central and culturally valued child characteristics that parents promote in child development. There is variance in whether parents emphasize, for example, the development of autonomy, independence, and sense of self or, alternatively, the abilities to obey, cherish relatedness, and maintain social harmony (Bornstein and Cote 2004; Keller et al. 2008; Vohringer et al. 2015).

Research shows that parents' education and economic resources, urban versus rural environment, and family size affect parenting beliefs (Kartner et al. 2010; Keller 2007). Autonomy-enhancing socialization goals, such as emphasizing children's own will and the expression of both positive and negative emotions, are characteristic among educated middle-class parents and nuclear families living in urban contexts. Conversely, relatedness-enhancing socialization goals, such as obedience and special respect for elders, are typical of caregivers with less education living in rural contexts.

The complex interplay of sociocultural values, parental education, income, and globalization creates societies that are intermediate rather than at one extreme of the individualism-collectivism continuum (Brewer 2007; Kagitcibasi 2005, 2012). For example, in Beijing, China, and Delhi, India, mothers' parenting beliefs emphasize the importance of both autonomy and relatedness (Keller 2007). Indeed, the concepts perhaps capture reality best when conceived as complementary rather than opposing or distinct categories (Kagitcibasi 2012).
It is estimated that 357 million children live in war-torn countries (Save the Children International 2018), including the participants in the current study - the Palestinian mother-infant dyads. Views of the impact of traumatic stress and life-danger on parenting beliefs are mixed, and empirical studies are few. Some suggest that war-traumatized parents enhance their children's independence and autonomy by rough, demanding, and insensitive rearing practices in order to prepare them to sustain themselves, survive, and thrive in dangerous environmental conditions (Belsky 2008; Marey-Sarwan et al. 2016). Others suggest instead that mothers exposed to severe war trauma tend to intensify their efforts to protect their children by enhancing relatedness and secure attachment through support, tenderness, and sensitivity to children's neediness (Barber et al. 2005; Palosaari et al. 2013). Yet research suggests that maternal trauma both burdens and complicates parenting and parent-child relationships, and some evidence is available on war trauma, terrorism (Kaitz et al. 2009; Van Ee et al. 2012), and interpersonal trauma, such as the mother's childhood maltreatment or abuse (Savage et al. 2019; Vaillaintcourt et al. 2017). However, there is no research to date on the impact of different types of trauma on parenting beliefs, which is important to understand as evidence shows that interpersonal trauma has more severe consequences for parental mental health than does collective trauma, such as war and especially natural disasters (McMillan and Asmundson 2016).

Israeli qualitative studies have shown that mothers exposed to a terrorist attack in pregnancy face difficulties in creating dyadic relationships as they feel incompetent and guilty for not being able to protect and provide safety for their children (Kaitz et al. 2009; Levy 2006). Van Ee et al. (2012) showed that refugee mothers who suffered from posttraumatic stress disorder (PTSD) symptoms showed a low level of emotional availability (EA) - that is, they were less sensitive and structuring and more hostile-toward their infants, who in turn were less responsive and involved in the dyadic interaction. A study among Palestinian mothers found, however, that mothers' severe traumatic war experiences were not directly associated with non-optimal mother-infant interaction, but rather that the impact was mediated through both low levels of maternal-fetus attachment (interacting, sharing, and fantasy) and family social support and a high level of prenatal and postnatal mental health problems (Punamäki et al. 2017).

Some evidence shows that interpersonal trauma, such as family violence and parents' own early emotional and physical abuse, has negative impacts on dyadic mother-infant interaction. Mothers with childhood abuse histories face difficulties in providing emotional security to their infants and may swing from neglect and withdrawal to hostility and intrusiveness and back again (Lyons-Ruth et al. 2006). Clinical observations suggest that the neediness and helplessness of an infant can activate painful memories, 
which then interferes with a mother's interaction with the infant, shown through withdrawal, hostility, and fear (Schechter and Willheim 2009). However, a meta-analysis showed only a rather minor, though significant, association between maternal abuse history and harsh parenting of young children (under 6 years; Savage et al. 2019). A systematic review further suggested that mothers' childhood abuse is associated with poor-quality dyadic interaction via maternal depression or psychophysiological reactivity rather than directly (Vaillaintcourt et al. 2017).

The prenatal and postnatal periods are crucial both for the formation of parenting beliefs and for laying the foundation for the mother-infant relationship and child development. Some studies suggest that parenting beliefs are important in determining family vulnerability versus resilience. Parenting that matches sociocultural socialization values can serve as a protective shield for maternal mental health and child development (Feldman and Masalha 2007; Triandis 2000). For example, Feldman and Masalha (2007) showed that individual, autonomy-promoting parenting, such as face-to-face interaction and indirect teaching, promoted Israeli toddlers' age-salient self-regulation, whereas proximal, relatedness-promoting parenting, such as bodily contact and concrete assistance, were beneficial to Palestinian toddlers. Exposure to traumatic war events-and especially the subsequent mental health problems of PTSD and depressive symptoms-might interfere with socioculturally salient parenting (Isosävi et al. 2020; Punamäki et al. 2018) and with optimal mother-infant relationships and infant development (Feldman et al. 2014; van Ee et al. 2012).

The meanings given to traumatic experiences and the emotional, social, and cognitive responses to them reflect sociopolitical and cultural contexts (Marsella 2010). The participants in this study were Palestinian mothers living in the Gaza Strip who belong to ancient Middle Eastern culture and practice Islam. Islamic writings consider parenting and the guidance of the next generation to be a highly valued and respected duty and privilege, emphasizing the parental urgency to protect the child and teach social, religious, and moral virtues (El Azayem and Hedayat-Diba 1994). To our knowledge, there has been no prior research into Palestinian mothers' parenting beliefs involving ethnotheories of opted rearing practices and socialization goals. The fact that families in the Gaza Strip are typically large, involve many generations in one household, and have access only to scarce material resources (UN-OCHA 2014: 2017) suggests that obedience, respect for elders, and consideration of others might be a favored socialization goal, reflecting the values of collectivism and relatedness. However, most Palestinians live in cities rather than rural environments, and women are highly educated (World Bank 2015), which would suggest an emphasis on individualistic and autonomy-enhancing parenting beliefs. The high stress and danger inherent in the Israeli military siege, wars, and military operations are also likely to play a role in mothers' construction of their ethnotheories about favorable rearing practices and early parenting and their socialization goals regarding culturally appropriate child characteristics.

The current three-wave prospective study among Palestinian mother-infant dyads investigated the role of traumatic experiences and mental health in parenting beliefs and their impact on mother-infant interactions and infant development. The research tasks were, first, to examine how mothers' traumatic experiences (current traumatic war events and childhood emotional and physical abuse) and prenatal maternal mental health problems (PTSD, depression, and anxiety symptoms) would be associated with their parenting beliefs (parenting ethnotheories and socialization goals) when their infants were four months old. The second task was to examine how parenting beliefs would be ere associated with the quality of mother-infant interaction (closeness and positive responses) and with infant development (language, fine-motor, and gross-motor skills) when the infants were 12 months old. The third task was to examine whether parenting beliefs mediated the impact of maternal traumatic experiences and mental health on mother-infant interaction and infant development.

\section{Methods}

\section{Participants}

The participants in this study were 511 pregnant Palestinian mothers living in the Gaza Strip. They were recruited in their second trimester of pregnancy (T1) from maternal clinics in ten governmental primary health care centers representing governorates in the North, Gaza City, Middle Area, Khan Youniss, and Rafah. The inclusion criteria were a residence in the above governorates and being in the second trimester of pregnancy. Of these women, 481 participated again when their infants were four months old (T2) and 454 when the infants were 12 months old (T3). Piloting was done with 42 pregnant women representing the five governorates. The Ethical Board of The Palestinian Ministry of Health approved the study protocol and measures. The women were provided with information on the study, and those who agreed to participate gave written consent.

The dropout rate from $\mathrm{T} 1$ to $\mathrm{T} 2$ was $5.9 \%(n=30)$. Reasons for dropping out were miscarriage $(n=10)$, errors in housing information $(n=8)$, unwillingness to participate $(n=3)$, inability to participate $(n=5)$, and infant death $(n=4)$. The dropouts were independent of the women's age, $\quad(F(1,509)=0.019, \quad p=$ ns. $)$ number of children 
$(F(1,509)=0.03, \quad p=\mathrm{ns}),. \quad\left(c^{2}(3,511)=0.51, \quad p=\mathrm{ns}.\right)$, economic status $\left(c^{2}(3,511)=0.81, p=\right.$ ns. $)$, war trauma $(F$ $(1,509)=0.36, p=\mathrm{ns}$.$) , and prenatal depression (F(1,509)$ $=0.60, p=\mathrm{ns}$.$) , PTSD (F(1,509)=0.69, p=\mathrm{ns}$.$) , and$ anxiety $(F(1,509)=1.84, p=\mathrm{ns}$. $)$ symptoms.

The dropout rate from T2 to T3 was $11.2 \%$ from T1 $(n=$ $57)$, mostly due to failures to locate the whereabouts of displaced women $(10.8 \%, n=55)$ and death $(n=2)$. The dropouts at T3 were also independent of the women's age $(F(1,509)=0.95, p=$ ns. $)$, number of children $(F(1,509)=$ $0.47, p=\mathrm{ns}$.$) , job status (c(3,511)=0.89, p=\mathrm{ns}$.$) , eco-$ nomic status $(c(3,511)=1.67 p=\mathrm{ns}$. $)$, war trauma at $\mathrm{T} 1(F$ $(1,509)=0.08, p=\mathrm{ns}$.$) , and prenatal depression (F(1,509)$ $=0.09, p=\mathrm{ns}$.$) , PTSD (F(1,509)=2.69, p=\mathrm{ns}$.$) , and$ anxiety $(F(1,509)=1.98, p=$ ns. $)$ symptoms. The dropouts were independent of newborn birth weight $(F(1,474)=$ $0.15, p=\mathrm{ns}$.$) , prematurity, (F(1,463)=2.39, p=\mathrm{ns}$.$) , and$ need for intensive care or hospitalization $(F(1,463)=0.03$, $p=\mathrm{ns}$.).

\section{Procedure}

The current study was conducted longitudinally during 2013-2015. The participants experienced major wars both before and during the study: the 2008/09 war on Gaza (Operation Cast Lead of the Israeli military) and the 2014 war on Gaza (Operation Protective Edge of the Israeli military), as well as the 2012 Israeli military operation. The 2008/09 war lasted 23 days and the 2014 war 54 days, with death tolls of 1417 and 2251, respectively. In the 2014 war, there were 11,231 wounded and 273,000 displaced Palestinians (UN Human Rights Council 2015; UN-OCHA 2014).

$\mathrm{T} 1$ was conducted in the health care centers, while $\mathrm{T} 2$ and T3 visits took place in the women's homes. Ten local fieldworkers with bachelor's degrees and prior experience in research work attended a comprehensive training on the research tasks and procedures, interviewing skills, ethical rules, and how to conduct home visits. The third and fourth authors provided the training and supervised the fieldwork in weekly consultative meetings. The research visits lasted between 60 and $90 \mathrm{~min}$. As some mothers were illiterate and many were unfamiliar with research practices, the fieldworkers interviewed the mothers and wrote down their answers instead of completing questionnaires.

\section{Measures}

\section{Demographic factors}

At $\mathrm{T} 1$, the women reported their age, number of children, and length of marriage through open questions, and accounted for their education (basic education [including primary and secondary school], vocational training, college, or university/polytechnic education), and employment (permanent work, part time work, unemployment, work at home, student, or other). To indicate the family's financial situation, women estimated on a 5-point scale their difficulties in paying bills and the sufficiency of their monthly income. Their answers were combined as (1) no difficulties and sufficient means, (2) some difficulties and somewhat insufficient means, or (3) substantial economic difficulties.

Mothers' traumatic experiences were assessed at $\mathrm{T} 1$ and comprised traumatic war events and childhood emotional and physical abuse.

\section{Traumatic war events}

The scale includes 28 typical war events during the war on Gaza in 2008/2009 and the 2012 military offensive (reference omitted for anonymity). Seven items asked about family losses and injuries (e.g., death or injury of family members and detention or separation in the family), six about material destruction (e.g., damaged property, loss of home, and destroyed neighborhood), nine about witnessing horrifying scenes (e.g., deaths and injuries of close people, explosions, and shelling), and six about threats to life (e.g., being afraid of dying). The women reported whether they had been exposed to these events in the last 5 years (yes = $1 ; n o=0)$. A sum score was constructed in which higher scores indicated an accumulation of diverse traumatic war events.

\section{Childhood abuse}

A 13-item questionnaire by the Transcultural Psychological Organization (Punamäki et al. 2005) probes experiences of emotional and physical abuse in relation to both the mother and father, covering up to the age of 12 . Seven items refer to emotional abuse (e.g., verbal threats, humiliation, and ridiculing) and four items to physical abuse (e.g., being slapped or beaten). The scale also includes two positive relational items that were omitted from the current analysis. Mothers reported how often they had experienced each type of abuse during their childhoods on a 5-point scale $(0=$ never; $4=$ always). A sum score was constructed in which higher scores indicated more severe parental childhood abuse.

Mothers' mental health problems were assessed at T1 by questionnaires of PTSD, depression, and anxiety symptoms.

\section{PTSD symptoms}

The 16-item symptom scale for PTSD from the Harvard Trauma Questionnaire (HTQ; Mollica et al. 1992) was used. The HTQ covers intrusive, avoidant, and hypervigilant 
symptoms. Mothers evaluated the degree to which they had suffered from the described symptoms during the last 30 days on a 4-point scale ranging from 0 (Not at all) to 3 (Severely). A sum variable was constructed for which the Cronbach's $\alpha$ was 0.89 .

\section{Depressive symptoms}

The Edinburgh Postnatal Depression Scale (EPDS; Cox et al. 1987) was used to measure depressive symptoms. The EPDS consists of ten items assessing depression-related thoughts, feelings, and behaviors. Mothers responded as to how often they had experienced the described symptoms during the last 2 weeks on a 4-point scale ranging from 1 (not at all) to 4 (every day). A sum variable was constructed for which the Cronbach's $\alpha$ was 0.77 .

\section{Pregnancy-related anxiety}

To assess anxiety, the study used the 10-item Pregnancy Anxiety Scale (PAS; Levin 1991), which covers anxiety and fears related to pregnancy, childbirth, and hospitalization. Women estimated how well the descriptions matched their feelings and thoughts using a 5-point Likert scale ranging from 1 (not at all) to 5 (a lot). A total sum variable was constructed for which the Cronbach's $\alpha$ was 0.80 .

Parenting beliefs about salient parenting practices (parenting ethnotheories) and salient child characteristics (parental socialization goals) were measured at T2.

\section{Parenting ethnotheories}

The Parenting Ethnotheories Scale (Keller et al. 2006) includes ten items that assess the explicit and implicit ideas of "good" or "right" parenting of approximately 3month-old babies. Five statements refer to relatednessoriented parenting beliefs, such as"If a baby is fussy, he/ she should be immediately picked up" or "The baby must always be close to his/her mother so that the mother can act immediately on his/her signals." Five statements indicate autonomy-oriented parenting beliefs, such as "Sleeping through the night should be trained as early as possible" or "The baby should be left crying for a moment to see if she/he can soothe and console her/ himself." Mothers responded on a 5-point Likert scale as to how strongly they believed each item to be important in their infant caring practices $(1=$ not agree at all; $5=$ fully agree). In the structural equation model (SEM) analyses, measurement models were constructed for separate relatedness-oriented and autonomy-oriented parental ethnotheory latent variables, both with five manifest variables.

\section{Parental socialization goals}

The Parental Socialization Goals Measure (Keller et al. 2006) has ten items describing characteristics that parents wish their children to acquire during the first 3 years of life. Five of the items measure autonomy-enhancing socialization goals, such as "Learn to respect elderly people," and five measure relatedness-enhancing socialization goals, such as "Develop self-confidence." For the current study, the measure was applied in a pairwise comparison form in which mothers were shown two randomly selected statements at the same time-one depicting an autonomous goal and the other depicting a relatedness goal-and asked to choose the one that they valued most (a total of five pairs). In the SEM analyses, measurement models were constructed for separate relatedness-enhancing and autonomyenhancing latent variables of parental socialization goals, both with five manifest variables.

\section{Infant-mother interaction at T3}

A short version of the Emotional Availability Self Report (EA-SR-Brief; Biringen et al. 2002) was used to evaluate infant-mother interaction at 12 months. The 28-item questionnaire covers items indicating high emotional availability (e.g., "My baby likes to be with me most of the time," "My baby seems to light up when she/he sees me," and "I am usually in a good mood when with my baby") and low availability (e.g., "My baby is "cranky' most of the time," "My baby doesn't seem to notice when I come back into the room," and "It is hard to soothe my baby and he (or she) seems to be distressed a lot.") The women estimated the extent to which the descriptions fit them and their babies on a 5-point Likert scale ( $1=$ not at all; $5=$ completely). The EA-SR-Brief self-assessment form is based on the observational Emotional Availability Scales and has been shown to correlate significantly with them (Vliegen et al. 2009). The EA-SR-Brief has not been validated among Palestinians or in other Middle Eastern samples. For the current study, sum variables were formed for close and positive dyadic interactions, which had good internal consistency $(\alpha=0.80)$, and for distant and negative interactions, which had insufficient consistency $(\alpha=0.55)$.

\section{Infant development at T3}

A 15-item questionnaire based on the Minnesota Child Development Inventory (MCDI; Kopparthi et al. 1991) was used to assess infants' vocalization, language utterances, and fine- and gross-motor development at 12 months. The items reflect increasingly demanding skills on three scales: the eight-item scale for language (e.g., from "Baby imitates repetitious baby talk, such as mama, papa" to "Baby 
combines two words"); the four-item scale for fine-motor development (e.g., from "Baby can hold a toy/thing using both hands" to "Baby can pick a small thing up using thumb and one finger"); and the three-item scale for gross-motor development (e.g., from "Baby moves and walks by supporting him/herself" to "Baby walks without support.") Mothers estimated on a 3-point scale whether the infant had performed the task $(1=$ not observed $; 2=$ observed once or occasionally; $3=$ observed many times, routinely). The MCDI has been validated and corresponds with Bayley Sensory Motor Skills in 8-16-month-olds in North American (Kopparthi et al. 1991) and Egyptian (Baherie 2013) samples. The current 15 -item scale has been validated for evaluation of early communication, language, and sensorimotor development among Finnish children (Lyytinen et al. 2000). A measurement model was constructed that involved a latent variable with three manifest variables of language, fine-motor skills, and gross-motor skills, with higher scores indicating advanced development.

\section{Translation}

The PTSD and war trauma questionnaires were already available in Arabic. The Parenting Ethnotheories Scale, Parental Socialization Goals Measure, and EA-SR-Brief were translated and back-translated by bilingual Palestinian research group members.

\section{Statistical Analysis}

The descriptive statistical analysis and computation of sum variables were performed using SPSS 24.0. The distributions of demographic variables and traumatic experiences are presented as percentages and the correlations between study variables as Pearson cross-products. To answer the research questions, a SEM with latent and manifest variables was performed using AMOS SEM (AMOS 24.0 software, SPSS Framework Version).

First, a measurement model of the latent study variables was constructed and tested with the maximum likelihood (ML) method to confirm the validity of the constructs and to determine their dimensionality. Second, an SEM model was constructed to analyze (a) how mothers' traumatic experiences and prenatal mental health reported at $\mathrm{T} 1$ would be associated with parenting ethnotheories and parental socialization goals at T2 and (b) how the parenting ethnotheories and parental socialization goals would then associate with mother-infant dyadic interaction and infant development at T3. The model also included direct paths between traumatic experiences and mental health (T1) and between dyadic interaction and infant development (T3).

In the SEM model, the exogenous variables were two manifest variables of current traumatic war events and childhood emotional and physical abuse and one latent variable of prenatal mental health (PTSD, depression, and anxiety symptoms). The endogenous variables consisted of two latent variables of parenting ethnotheories (autonomyoriented with five manifest variables and relatednessoriented with five manifest variables) and two parental socialization goals (autonomy-enhancing with five manifest variables and relatedness-enhancing with five manifest variables). They were regressed on the exogenous manifest variables of current traumatic war events, childhood abuse, and mental health. To indicate the role of the parental ethnotheories and socialization goals in associating with the quality of dyadic mother-infant interaction and infant development, one manifest variable of the quality of mother-infant interaction (close and positive) and the latent variable of infant development (language, fine-motor skills, and gross-motor skills) were regressed on the four endogenous latent variables of parenting ethnotheories and parental socialization goals.

Finally, we analyzed whether parenting beliefs would mediate the possible associations between traumatic experiences and mental health (predictors) on the one hand and dyadic interaction and infant development (outcomes) on the other. Two statistical criteria were used to detect mediation or indirect effects: (1) statistically significant paths ( $\beta$-values) between the predictors and the parenting ethnotheories and parental socialization goals and between the parenting beliefs and the outcomes and (2) significant indirect effects-bvalues (unstandardized beta) with confidence intervals (CI) that exclude zero. AMOS calculates indirect effects using an ML method that obtains estimates of the parameters and produces bias-corrected bootstrap CIs (MacKinnon et al. 2004). Eight covarying error terms were allowed within the manifest variables of relatedness- and autonomy-enhancing socialization goals.

The criteria for model fitness were a non-significant $\chi^{2}$ value, a comparative fit index (CFI) and Tucker-Lewis index (TLI) above 0.90, and a root mean square error of approximation (RMSEA) below 0.06 (Bentler, 2007). To perform a bootstrap analysis for indirect effects (mediation) requires complete data, and, for that purpose, a regression imputation was conducted. The missing values were not replaced in the final measurement model or in the SEM analysis.

\section{Results}

\section{Descriptive Statistics}

Table 1 presents the mother- and infant-related background information. A majority of mothers $(80 \%)$ were under 30 years old and $18 \%$ were expecting their first child. They had 
Table 1 Mother and infant background information

\begin{tabular}{|c|c|c|}
\hline & \multicolumn{2}{|c|}{ Participants } \\
\hline & $\%$ & $n$ \\
\hline \multicolumn{3}{|l|}{ Mother-related information } \\
\hline \multicolumn{3}{|l|}{ Age (years) } \\
\hline $16-20$ & 26.6 & 136 \\
\hline $21-30$ & 53.6 & 274 \\
\hline $31-40$ & 18.2 & 93 \\
\hline $41-46$ & 1.6 & 8 \\
\hline \multicolumn{3}{|l|}{ Number of children } \\
\hline Expecting the first child & 18.1 & 90 \\
\hline $1-3$ & 58.9 & 292 \\
\hline $4-6$ & 20.0 & 99 \\
\hline $7-11$ & 3.0 & 15 \\
\hline \multicolumn{3}{|l|}{ Length of marriage } \\
\hline$<1$ year & 8.8 & 45 \\
\hline $1-5$ years & 45.2 & 231 \\
\hline $6-10$ years & 26.4 & 135 \\
\hline $11-20$ years & 17.6 & 90 \\
\hline$>20$ & 1.8 & 9 \\
\hline \multicolumn{3}{|l|}{ Education } \\
\hline No formal education & 1.2 & 6 \\
\hline Elementary school & 11.4 & 58 \\
\hline Secondary school & 55.6 & 284 \\
\hline High school & 3.3 & 17 \\
\hline University or polytechnic college & 26.6 & 136 \\
\hline Other & 2.0 & 10 \\
\hline \multicolumn{3}{|l|}{ Job status } \\
\hline Working outside the home & 3.9 & 20 \\
\hline Home taking care of the children & 82.4 & 421 \\
\hline Student & 9.8 & 50 \\
\hline Unemployed or other & 3.9 & 20 \\
\hline \multicolumn{3}{|l|}{ Economic situation: sufficiency of money } \\
\hline Enough money & 45.4 & 232 \\
\hline Not enough money to cover expenses & 54.6 & 279 \\
\hline \multicolumn{3}{|l|}{ Economic situation: Difficulty to pay bills } \\
\hline No or some & 59.1 & 302 \\
\hline Very or extremely & 40.9 & 209 \\
\hline \multicolumn{3}{|l|}{ Infant-related information } \\
\hline \multicolumn{3}{|l|}{ Child sex } \\
\hline Girl & 45.7 & 219 \\
\hline Boy & 54.3 & 260 \\
\hline \multicolumn{3}{|l|}{ Gestational age (weeks) } \\
\hline$<37$ & 5.4 & 18 \\
\hline 37 and later & 94.6 & 318 \\
\hline \multicolumn{3}{|l|}{ Birth weight $(\mathrm{g})$} \\
\hline$<2500$ & 8.4 & 43 \\
\hline $2500-3499$ & 54.6 & 279 \\
\hline
\end{tabular}

Table 1 (continued)

\begin{tabular}{|c|c|c|}
\hline & \multicolumn{2}{|c|}{ Participants } \\
\hline & $\%$ & $n$ \\
\hline $3500-4499$ & 28.4 & 145 \\
\hline$>4500$ & 1.8 & 9 \\
\hline $55-65$ & 10.5 & 46 \\
\hline \multicolumn{3}{|l|}{ Infant health } \\
\hline Prematurity & 5.4 & 18 \\
\hline Need for NICU ${ }^{a}$ & 14.2 & 67 \\
\hline Need for later hospitalization & 9.1 & 43 \\
\hline
\end{tabular}

${ }^{\mathrm{a}} \mathrm{NICU}=$ Neonatal intensive care unit

1-11 children, the average being $2.22(S D=1.90)$. Most mothers $(80 \%)$ had been married for 1-10 years, the average being $6.49(S D=4.83)$. More than half $(56 \%)$ had finished secondary school and almost a third (27\%) polytechnic college or university. A majority (82\%) worked at home caring for their children and the extended family. Financial difficulties were common: about half (54\%) of the women reported their family having difficulties in covering everyday needs and paying bills.

Of the infants, $54 \%$ were boys and $46 \%$ girls. Three quarters $(75 \%)$ of newborns had a normal birth weight (2500-4000 g) and 8\% a low birth weight (below 2500 g); $5 \%$ were born prematurely, $14 \%$ needed extra hospital care in the newborn period, and $9 \%$ needed it later in the first six months.

Nearly all the participating mothers reported exposure to at least one traumatic war event during the 2008-2009 war on Gaza. About two-thirds $(65.6 \%, n=292)$ had to flee due to shelling of their homes, about half had faced material destruction $(55.9 \%, n=284)$, and about a quarter $(26.4 \%$, $n=134)$ had lost a close person.

Experiences of childhood emotional and physical abuse were common. Almost half of the mothers reported being scared by their parents (fathers $45.5 \%, n=227$; mothers $46.5 \%, n=234$ ), as well as being humiliated and parents shouting to them (fathers $41.9 \%, n=211$; mothers $45.1 \%, n=228$ ). More than a third reported about threats of being beaten (fathers $37.1 \%, n=187$; mothers $38.3 \%, n=193$ ).

Considering parenting ethnotheories, the mothers emphasized, on average, relatedness-oriented $(M=21.46$; $S D=2.95)$ over autonomy-oriented $(M=15.13 ; S D=$ 3.81) rearing practices [paired $t$-test: $t(461)=27.20, p=$ $0.0001]$. They also preferred relatedness-enhancing socialization goals slightly more than autonomous goals (ratio score $M=1.12 ; S D=0.36$, on a scale of $0-2$ ). However, for single socialization goals, the three most important single skills that mothers wished their children would develop were a combination of relatedness- and 
autonomy-enhancing socialization goals: "learning to obey parents" (relatedness; $M=1.85 ; S D=0.36$ ), "developing competitiveness" (autonomy; $M=1.72 ; S D=0.38$ ), and "developing self-confidence" (autonomy; $M=1.70 ; S D=$ 0.46). Likewise, the three least preferred skills included a mixture of autonomy- and relatedness-enhancing socialization goals: "learning to obey elderly people" (relatedness; $M=1.30 ; \quad S D=0.46$ ), "developing a sense of self" (autonomy; $M=1.33 ; S D=0.47$ ), and "learning to cheer up others" (relatedness; $M=1.43 ; S D=0.49$ ).

\section{Measurement Models of Latent Variables}

Table 2 presents the SEM measurement models of the latent constructs of maternal mental health, relatedness- and autonomy-oriented parenting ethnotheories, and relatedness- and autonomy-enhancing parental socialization goals, as well as infant development. The latent variable of mother-infant interaction with two manifest variables failed to be identified and was omitted from the measurement model. A manifest sum variable was constructed for further analysis by summing the close, positive sum scores and the distant, negative sum scores, with high values indicating high-quality interaction (close and positive).

The results of the measurement model show good fit indices for the measure model $(\mathrm{CFI}=0.94$; $\mathrm{TLI}=0.93$; RMSEA $=0.059$ [90\% CI: 0.059-0.065], although $\chi^{2}$ (624.38, $\mathrm{df}=225, p=0.0001)$ was significant, as is often the case with large samples (Hu and Bentler 1999). All manifest variables loaded statistically significantly on each of the six latent variables, except for one of the autonomyoriented parenting ethnotheories latent variables ("sleeping through the night should be trained as early as possible"). That manifest variable was kept in the analysis for conceptual balance. Also, although statistically significant, the estimation loadings- $\beta$-values - were low for the parental autonomy-oriented parenting ethnotheories latent variable and both the relatedness-enhancing and the autonomyenhancing socialization goals latent variables. This may reflect the fact that mothers preferred both autonomy- and relatedness-enhancing goals, rather than one or the other, as was statistically expected.

\section{Trauma and Mental Health Associating with Parenting Ethnotheories and Socialization Goals}

The SEM model that tested simultaneous paths from traumatic experiences to the parenting ethnotheories and the parental socialization goals and their further impacts on mother-infant dyadic interaction and infant development showed adequate goodness-of-fit: $\mathrm{CFI}=0.92$; TLI $=0.91$; RMSEA $=0.054$ [90\% CI: 0.050-0.059]. However, the $\chi^{2}$-value was significant $\chi^{2}=938.15, \mathrm{df}=374, p=0.0001$ ), as is often the case in large samples (Hu and Bentler 1999).

Figure 1 and Table 3 show the results of the SEM and indicate that both types of maternal traumatic experiences associated with relatedness- and autonomy-enhancing parental socialization goals. The associations were specific to the trauma type and of an opposing nature. A high level of current traumatic war events were associated with higher levels of autonomy-enhancing $(\beta=0.13, t=3.01, p=$ $0.003)$ and lower levels of relatedness-enhancing $(\beta=-16$, $t=-3.36, p=0.0001)$ parental socialization goals. Conversely, a high level of childhood emotional and physical abuse were associate with higher levels of relatednessenhancing $(\beta=0.09, t=2.00, p=0.050)$ and lower levels of autonomy-enhancing $(\beta=-0.09, t=-2.12, p=0.030)$ parental socialization goals. As shown in Table 3, neither current traumatic war events nor childhood abuse were associate with autonomy- or relatedness-oriented parenting ethnotheories. The results further showed that maternal prenatal mental health, as indicated by PTSD, depression, and anxiety symptoms, did not associate with either parenting ethnotheories or parental socialization goals.

\section{Parenting Beliefs Associating with Dyadic Interaction and Infant Development}

The results in Table 3 reveal only two marginally significant $\beta$ values between parental socialization goals and infant development. Both high relatedness-enhancing $(\beta=0.22, t=1.76$, $p=0.08)$ and high autonomy-enhancing $(\beta=0.18, t=1.66$, $p=0.10$ ) socialization goals were associate with advanced language, gross-motor, and fine-motor infant development.

Neither parenting ethnotheories nor parental socialization goals were associate with mother-infant dyadic interaction, but statistically significant direct paths were found from maternal traumatic experiences and mental health to dyadic mother-infant interaction. A high level of traumatic war events were associate with a high level of close and positive interaction $(\beta=0.12, t=2.44, p=0.01)$, whereas childhood emotional and physical abuse were associated with a low level of close and positive interaction $(\beta=-0.13, t=$ $-2.70, p=0.007$ ). A high level of prenatal maternal mental health problems also were associated with lower levels of close and positive interaction $(\beta=-0.17, t=-2.73, p=$ 0.004). Neither traumatic experiences nor mental health problems showed direct associations with infants' language, fine-motor, or gross-motor development.

Concerning mediation tests, the results showed only marginally significant associations between parental socialization goals and infant development and showed non-significant associations with dyadic interaction, thus failing to fulfill the first premise for indirect links. Subsequently, the mediating 
Table 2 Loading estimates of manifest variables of maternal mental health, parenting ethnotheories, parental socialization goals, and infant development for corresponding latent constructs of the Structural Equation Model (SEM)

\begin{tabular}{|c|c|c|c|c|}
\hline Manifest variables for latent constructs & Unstd $\beta$ & SE & Std $\beta$ & $t$-tests ${ }^{\mathrm{b}}$ \\
\hline \multicolumn{5}{|l|}{ Maternal mental health problems at $\mathrm{T}^{\mathrm{a}}$} \\
\hline PTSD-symptoms ${ }^{\mathrm{c}}$ & 1.00 & & 0.83 & \\
\hline Depressive symptoms & 0.32 & 0.07 & 0.56 & $4.61 * * * *$ \\
\hline Anxiety symptoms & 0.28 & 0.06 & 0.33 & $4.32 * * * *$ \\
\hline \multicolumn{5}{|l|}{ Relatedness-oriented parental ethnotheories at $\mathrm{T}^{\mathrm{a}}$} \\
\hline Important to rock a crying baby on the arms in order to console him & 1.00 & . & 0.31 & \\
\hline Gymnastics make a baby strong & 0.28 & 0.14 & 0.13 & $2.02 *$ \\
\hline A fussy baby should be immediately picked up & 1.29 & 0.30 & 0.52 & $4.32 * * * *$ \\
\hline A crying baby should be nursed immediately & 1.69 & 0.39 & 0.58 & $4.33 * * * *$ \\
\hline $\begin{array}{l}\text { A baby should be always in close proximity with the mother, so that } \\
\text { she can react immediately to baby's signals }\end{array}$ & 1.04 & 0.24 & 0.48 & $4.26 * * * *$ \\
\hline \multicolumn{5}{|l|}{ Autonomy-oriented parental ethnotheories at T2 } \\
\hline $\begin{array}{l}\text { Babies should be left crying for a moment in order to see whether } \\
\text { they console themselves }\end{array}$ & 1.00 & . & 0.54 & \\
\hline Sleeping through the night should be trained as early as possible & 0.16 & 0.14 & 0.09 & 1.17 \\
\hline It is not necessary to react immediately to a crying baby & 0.46 & 0.19 & 0.23 & $2.45^{* *}$ \\
\hline $\begin{array}{l}\text { Importance to start early enough to direct the baby's attention } \\
\text { towards objects and toys }\end{array}$ & 0.42 & 0.18 & 0.21 & $2.35^{*}$ \\
\hline It is good for the baby to sleep alone & 0.86 & 0.32 & 0.43 & $2.64 * *$ \\
\hline \multicolumn{5}{|l|}{ Relatedness-enhancing parental socialization goals at $\mathrm{T} 2$} \\
\hline Learn to obey parents & 1.00 & & 0.97 & \\
\hline Learn to respect elderly people & 0.27 & 0.04 & 0.21 & $6.31 * * * *$ \\
\hline Learn to care for wellbeing of others & 0.15 & 0.05 & 0.11 & $3.35 * * * *$ \\
\hline Learn to cheer up others & 0.22 & 0.05 & 0.17 & $4.82 * * * *$ \\
\hline Learn to control emotions & 0.18 & 0.04 & 0.14 & $4.14 * * * *$ \\
\hline \multicolumn{5}{|l|}{ Autonomy-enhancing parental socialization goals at $\mathrm{T} 2$} \\
\hline Develop competitiveness & 1.00 & & 0.58 & \\
\hline Develop self-confidence & 0.20 & 0.04 & 0.17 & $4.99 * * * *$ \\
\hline Develop a high self-esteem & 0.16 & 0.04 & 0.12 & $3.82 * * * *$ \\
\hline Develop independence & 0.19 & 0.04 & 0.16 & $4.44 * * * *$ \\
\hline Develop a sense of unique self & 0.12 & 0.04 & 0.10 & $3.25 * * *$ \\
\hline \multicolumn{5}{|l|}{ Infant development at $\mathrm{T}^{\mathrm{a}}$} \\
\hline Language skills & 1.00 & & 0.83 & \\
\hline Fine-motor skills & 0.86 & 0.05 & 0.82 & $17.41 * * * *$ \\
\hline Gross-motor skills & 0.60 & 0.04 & 0.75 & $16.66 * * * *$ \\
\hline \multicolumn{5}{|l|}{ Model indices } \\
\hline \multicolumn{5}{|l|}{$\chi^{2}=624.38, \mathrm{df}=225, p=0.0001 ; \mathrm{CFI}=0.94 ; \mathrm{TLI}=0.93$} \\
\hline RMSEA $=0.059$ [90\% CI: 0.049-0.065] & & & & \\
\hline
\end{tabular}

$* p<0.05 ; * * p<0.01 ; * * * p<0.001 ; * * * * p<0.0001$

${ }^{\mathrm{a}} N=511$ at $\mathrm{T} 1, N=446$ at $\mathrm{T} 2 ; N=373$ at $\mathrm{T} 3$

${ }^{\mathrm{b}}$ In the Unstandardized estimate $(\beta)$ StdE (Unstandardized estimate) and $t$ values refer to parameters fixed to 1 in the measurement mode

${ }^{\mathrm{c}} \mathrm{PTSD}=$ posttraumatic stress disorder

role of parenting beliefs between mother's traumatic experiences and mental health and mother-infant dyadic interaction and infant development was not further tested with the second premise (bootstrap analysis with CIs).

\section{Discussion}

The results reveal that the type of traumatic experience is decisive in the mother's parenting beliefs about the 


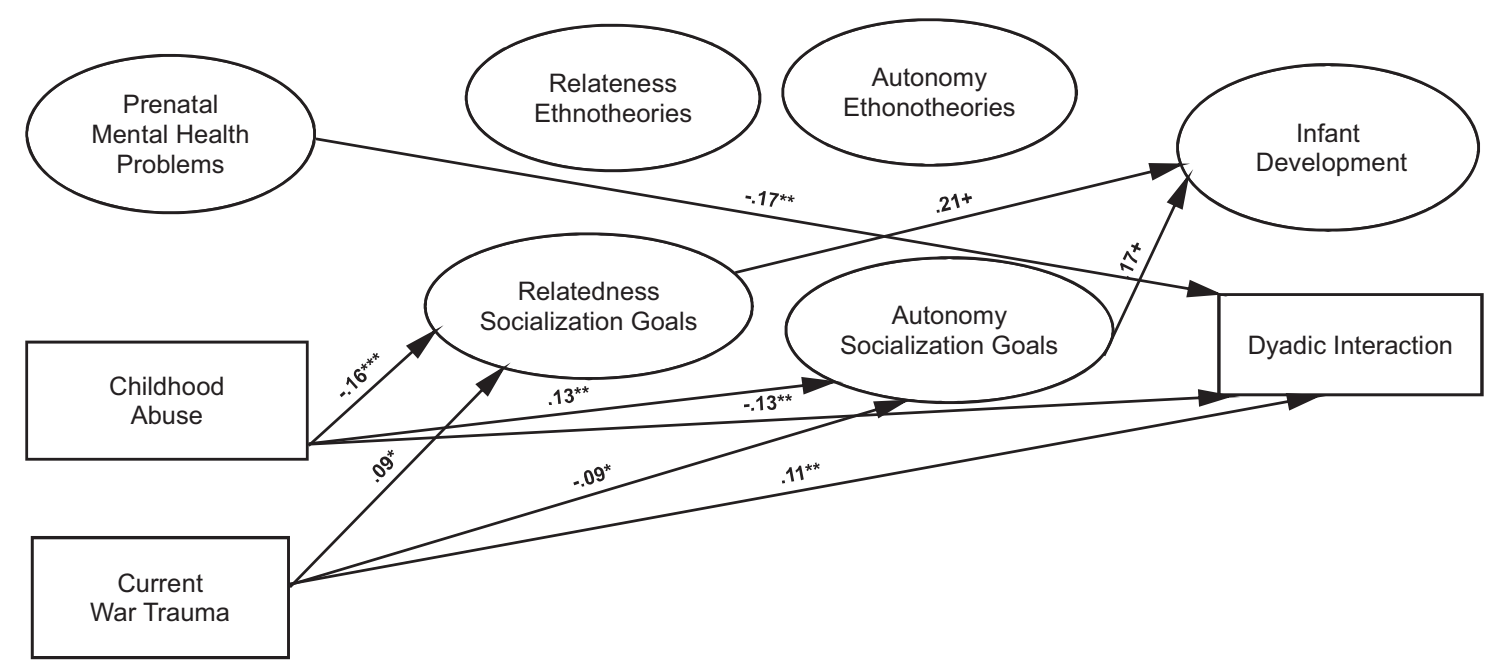

Fig. 1 Structural equation model (SEM) results of the traumatic experiences associating with parenting beliefs, and their impacts on mother-infant interaction and infant development. $N=452-511$. Standardized $\beta$-coefficients. ${ }^{* * *} p<0.001 ;{ }^{* *} p<0.01 ; * p<0.05$. Only

effective, apt, and favorable characteristics of the child and the childrearing practices. Mothers exposed to severe current traumatic war events preferred children's autonomyenhancing socialization goals and reported close and positive qualities in mother-infant interaction. In contrast, mothers with severe childhood emotional and physical abuse favored relatedness-enhancing socialization goals but reported low levels of close and positive interactions with their 1-year-olds. Maternal prenatal mental health problems were not associated with parenting beliefs, but instead were associated with low close and positive dyadic interaction. Concerning infant development, a tendency was found for mothers' high levels of both autonomy- and relatednessenhancing socialization goals to be associated with advanced infant language and motor development.

\section{Endorsing Both Relatedness and Autonomy}

Importantly, Palestinian mothers endorsed both autonomy and relatedness in their parenting beliefs. This finding concurs with the idea that high-stress and dangerous environments require diversity and flexibility of parenting beliefs in order to guarantee the success of one's offspring (Belsky 2008; Keller 2007) and the idea that individual and collectivistic values are not opposing, but rather complementary and dynamic (Kagitcibasi 2005).

In the Palestinian context, mothers face a dual demand to socialize their infants to relatedness, involving culturally apt respect for the elderly and human dignity in large and extended families, and, in parallel, to prepare them with the autonomy that is necessary in the face of military conflict and war violence. This might be a rationale for the mothers to simultaneously emphasize the importance of children's significant path regression estimates are shown. Error terms and correlations and correlated residuals/error terms are omitted for clarity reason. For a description of manifest variables and fixed estimates, see Table 2

obedience and harmony-seeking and their independence and competitiveness. Although marginally significant, the finding that high levels of both autonomy- and relatednessenhancing socialization goals were associated with advanced cognitive, language, and sensorimotor development is important here. It might suggest that the strength, integrity, and meaningfulness of the maternal socialization strategy promotes child development in high-stress and dangerous contexts, rather than the specific goals that she may choose.

In future studies, it would be informative to investigate the specific and dynamic profiles of diverse parenting beliefs instead of a general group-level analysis of either relatedness or autonomy. Examination of unique profiles or clusters might reveal specific goodness-of-fit dynamics between parenting beliefs and the demands of a given context.

\section{The Nature of Trauma Matters}

The childhood trauma of parental abuse and current traumatic war events played opposing roles in mothers' socialization goals. The result that mothers exposed to losses, atrocities, and threats to life during war favored autonomy-enhancing socialization goals supports the idea that children living in war-zones must be self-reliant, active, and courageous from an early age. The literature describes "war children" as those growing up quickly and acquiring adult responsibilities too early (Singer 2006). As the highly war trauma-exposed mothers also reported high-quality interactions with their infants, we might suggest that enhancing autonomy reflects a dyadic adaptation to the demands posed by the military dangers. Thus, historical, sociopolitical, and military 
Table 3 Structural Equation Model (SEM) on predictors (traumatic experiences and maternal mental health) of parenting beliefs and their outcomes (mother-infant dyadic interaction and infant development): parameter estimates ( $\beta$-coefficients) and model fit indices

\begin{tabular}{|c|c|c|c|c|}
\hline & Unstdized $\beta$ & S.E. & Stdardized $\beta$ & $t$-tests \\
\hline \multicolumn{5}{|l|}{ Direct paths between predictors and consequences } \\
\hline Traumatic war events $->$ Mother-infant interaction & 0.21 & 0.09 & 0.12 & $2.44 * *$ \\
\hline Childhood abuse -> Mother-infant interaction & -0.16 & 0.06 & -0.13 & $-2.70 * *$ \\
\hline Mental health problems -> Mother-infant interaction & -0.17 & 0.06 & -0.17 & $-2.73 * *$ \\
\hline Traumatic war events -> Infant development & 0.02 & 0.01 & 0.06 & 1.23 \\
\hline Childhood abuse -> Infant development & -0.01 & 0.01 & -0.01 & -0.05 \\
\hline Mental health problems -> Infant development & 0.01 & 0.01 & 0.07 & 1.11 \\
\hline \multicolumn{5}{|l|}{ Paths between predictors and parenting ethnotheories } \\
\hline Traumatic war events $->$ Relatedness-oriented ethnotheories & 0.01 & 0.01 & 0.04 & 0.60 \\
\hline Childhood abuse -> Relatedness-oriented ethnotheories & 0.01 & 0.01 & 0.06 & 0.89 \\
\hline Mental health problems $->$ Relatedness-oriented ethnotheories & -0.01 & 0.01 & -0.08 & -1.00 \\
\hline Traumatic war events -> Autonomy-oriented ethnotheories & -0.01 & 0.01 & -0.05 & -0.71 \\
\hline Childhood abuse -> Autonomy-oriented ethnotheories & -0.01 & 0.01 & 0.03 & 0.39 \\
\hline Mental health problems $->$ Autonomy-oriented ethnotheories & -0.01 & 0.01 & -0.03 & -0.34 \\
\hline \multicolumn{5}{|l|}{ Paths between predictors and parental socialization goals } \\
\hline Traumatic war events $->$ Relatedness-enhancing socialization goals & -0.01 & 0.01 & -0.16 & $-3.36 * * * *$ \\
\hline Childhood abuse -> Relatedness- enhancing socialization goals & 0.01 & 0.01 & 0.09 & $2.00 *$ \\
\hline Mental health problems $->$ Relatedness-enhancing socialization goals & 0.01 & 0.01 & 0.07 & 1.17 \\
\hline Traumatic war events $->$ Autonomy-enhancing socialization goals & 0.01 & 0.01 & 0.13 & $3.01 * *$ \\
\hline Childhood abuse -> Autonomy-enhancing socialization goals & -0.01 & 0.01 & -0.09 & $-2.12 *$ \\
\hline Mental health problems $->$ Autonomy- enhancing socialization goals & -0.01 & 0.01 & -0.04 & -0.68 \\
\hline \multicolumn{5}{|l|}{ Paths between parenting beliefs and dyadic interaction } \\
\hline Relatedness-oriented etnotheories -> Mother-infant interaction & 0.22 & 0.30 & 0.07 & 1.11 \\
\hline Autonomy-oriented etnotheories -> Mother-infant interaction & 0.62 & 0.60 & 0.02 & 0.32 \\
\hline Relatedness-enhancing socialization goals $->$ Mother-infant interaction & 0.42 & 0.12 & 0.16 & 1.39 \\
\hline Autonomy- enhancing socialization goals -> Mother-infant interaction & 0.82 & 0.47 & 0.11 & 1.13 \\
\hline \multicolumn{5}{|l|}{ Paths between parenting beliefs and infant development } \\
\hline Relatedness-oriented etnotheories $->$ Infant development & -0.04 & 0.23 & -0.01 & -0.16 \\
\hline Autonomy-oriented etnotheories -> Infant development & 0.04 & 0.14 & 0.02 & 0.28 \\
\hline Relatedness-enhancing socialization goals-> Infant development & 0.82 & 0.46 & 0.22 & $1.76+$ \\
\hline Autonomy-enhancing socialization goals -> Infant development & 0.62 & 0.37 & 0.18 & $1.66+$ \\
\hline Gender as covariant $->$ Mother-infant interaction & 0.10 & 0.92 & 0.06 & 1.19 \\
\hline Gender as covariant $->$ Infant development & 0.02 & 0.13 & 0.01 & 0.12 \\
\hline \multicolumn{5}{|l|}{ Model fit indices } \\
\hline \multicolumn{5}{|l|}{$\chi^{2}=938.15, \mathrm{df}=374, p=0.0001, \mathrm{CFI}=0.92, \mathrm{TLI}=0.91$} \\
\hline RMSEA $=0.054$ [90\% CI: $0.050-0.059]$ & & & & \\
\hline
\end{tabular}

conditions result in these mothers declining to endorse the traditional relatedness-centered values that are characteristic of collectivistic societies. It is also possible that the dyadic interactions that are coded as close and positive in the applied emotional availability paradigm (Biringen et al. 2002) tap on the same characteristics as the preference for autonomous socialization goals: the individualistic values viewing the infant as a separate, unique person whose needs the caregiver should sensitively fulfill (Keller 2013).
Our results provide an example of parents' experiences of military oppression and war trauma changing traditionally desired socialization goals and parenting strategies to better fit with current sociopolitical demands. Palestinian history and resistance against the Israeli military occupation has taught parents that emphasizing relatedness and the maintenance of harmony has not succeeded in gaining national independence and self-determination, and, subsequently, they promote more the values of strength and 
courage that better suit the aims of liberating the nation (Qouta et al. 2008; Hammami and Tamari 2001). The loss of land and persecution have apparently shaped the cultural scripts toward an emphasis on autonomy, activity, and selfsufficiency as salient survival skills.

In contrast, mothers with a history of childhood emotional and physical abuse endorsed relatedness-enhancing socialization goals, such as obedience, taking care of others, and suppressing emotions. This finding has multiple possible explanations. First, research among Euro-American mothers exposed to childhood abuse has found that, rather than reflecting on infant communication and situational demands, abused mothers tend to repeat the same authoritarian parenting practices that they experienced from their own parents (Schechter and Willheim 2009; Slade 2005). However, one can also expect that parents motivation is to protect the child, and they hope that their children will cherish the same characteristics that maybe helped themselves as children to cope with maltreatment or harsh parenting, such as obedience and suppressing one's own needs. Second, emphasis on obedience and the suppression of negative emotions might serve to protect the mother herself from high levels of stress that the infant's expression of distress can evoke among mothers traumatized by their childhood abuse (Schechter and Willheim 2009). Third, the tendency to keep children close might reflect a "tend and befriend" nurturing response-or even overprotection-that the abusive childhood memories can catalyze in mothers (Taylor et al. 2000). Due to these complex impacts of mother's own childhood emotional and physical abuse on mothers' socialization goals, it is understandable that they also reported a low level of emotionally close and positive dyadic interaction. They could instead rely on proximal bodily contact and direct guidance, which do not tap into sensitivity to the infant's unique needs but can be beneficial in the Palestinian traditionally collectivistic context (Feldman et al. 2006).

The finding of the importance of the nature of trauma uniquely shaping mothers' socialization goals emphasizes the meaningfulness of parenting values, goals, and ideals that match different living environments and personal histories (Keller 2003, 2007). Cultures share learned behaviors and meanings that are acquired in dynamic and changing living environments and passed from one generation to another for the purpose of promoting survival, adjustment, and thriving (Marsella and Yamada 2000, p. 12). However, maternal traumatic experiences were only associated with the socialization goals for the desired child characteristics, but not with parenting ethnotheories describing preferred infant-rearing practices. It might be that the actual parenting styles, rearing, and practical guidelines are more "fixed" and culturally embedded in everyday infant care, whereas the maternal values, ideals, and goals that shape children's skills are more changeable to fit culture and living environments in order to enhance children's chances of adapting and blooming (Marey-Sarwan et al. 2016).

Interestingly, only the socialization goals werealthough only marginally - associated with more advanced infant development, but neither parental socialization goals nor ethnotheories were associated with the quality of mother-infant interaction. The findings therefore differ from those of Keller and her group that showed that relatedness-enhancing parenting beliefs were associated with proximal and autonomy-enhancing with distal mother-infant interaction patterns (Keller et al. 2011; Keller 2007). These earlier findings fit well with the hypothesis that practical infant-rearing practices reflect and correspond to wider cultural ideas of uniquely apt human characteristics (Keller 2007).

However, it is important to remember that socialization goals did not mediate the impact of current traumatic war events or childhood abuse on mother-infant interaction or on infant development. In other words, the autonomyenhanced versus relatedness-enhanced socialization goals did not explain the important direct links between trauma and dyadic interaction, which indicated that current war trauma increased, and mother's own childhood emotional and physical abuse reduced, close and positive dyadic interaction. One reason for traumatic war events associating with high close and positive dyadic interaction may relate to the observation that parents invest intensively in the next generation while life is threatened by war (Punamäki 2014). Mothers may also enjoy especially high social support, encouragement, and even admiration when exposed to enemy violence and visible war atrocities. The national struggle for independence demands collective persistence, endurance, and heroism, which can be reflected in mother-infant interactions in the war-traumatized Palestinian community. Mothers exposed to maltreatment by own parents, in turn, may not have access to this support, sharing, and sense of belonging, and feel rather stigmatized in their community (Punamäki et al. 2005).

The current study did not find associations between a mother's mental health problems and her parenting beliefs. Instead, mothers with high levels of prenatal PTSD, depression, or anxiety symptoms reported less close and positive mother-infant interactions with their 1-year olds. That result concurs with ample evidence showing that prenatal maternal mental health problems-especially depression-create a severe risk for non-optimal mother-infant interaction (Field 2011; Glover 2014). We may speculate that, because of the urgency to survive in war conditions, maternal mental health is more directly reflected in her actual and practical behavioral patterns within dyadic interactions with her baby than in the parental beliefs that reflect philosophy, values, ideals, and preferences for early 
parenting and child characteristics. Good mental health contributes importantly to mothers' capacity to soothe a distressed infant, to recognize and legitimize her/his expressed emotions, and to provide feelings of safety (Field 2011). Parenting beliefs are, in contrast, more abstract, and thus their contents can remain more "intact" when mothers suffer from mental health problems. We did not offer hypotheses about how maternal prenatal mental health problems would be associated with preferences for either autonomy or relatedness of parenting beliefs because our study was the first to focus on their interplay in war conditions. Further research is needed to understand the meanings of mental health in parental ethnotheories and socialization goals.

Overall, the Palestinian mothers reported a high level of traumatic war events; for instance, more than a half had to flee with their infants from their shelled homes and a quarter had lost a beloved person. Childhood emotional and physical abuse was also common, as almost half reported parental abuse, such as threats of being beaten or being slapped. Some research suggests that childhood physical and emotional abuse might be especially prevalent in war conditions due to the high burdens of stress and the often impossible demands for parents to protect and provide safety for their children (Saile et al. 2014). Our study was the first to analyze the combined roles of these different types of traumatic experiences on parenting beliefs in early motherhood. Further research is warranted, as becoming a parent is a prime period for deciding which cultural traditions, rearing practices, and values one wishes to transfer to the next generation (Bravo and Noya 2014; Keller 2003). We would suggest that, while following certain cultural scripts, this transition also creates novel and meaningful practices that reflect the goodness-of-fit between societal demands and parenting beliefs.

\section{Strengths and Limitations of the Study}

The strengths of the study relate to the research setting. A large dataset collected in an ongoing war context helps to underpin some of the mechanisms involved in the variation of culturally regulated parenting values and beliefs and the mechanisms of intergenerational trauma. The research setting allows a combination of trauma research, cross-cultural developmental theories, and infant psychology. The longitudinal study had a very low dropout rate and focused on one of the most important life periods that forms the basis for child development and shapes parenthood. Our Palestinian fieldworkers were very welcome in the participants' homes, indicating - in addition to cultural hospitabilitythe mothers' willingness to share their experiences of parenting and infant development despite, or because of, extremely harsh war conditions.
Yet the study deserves criticism for single-source data, insensitivity to cultural aspects in some methods, and psychometric deficits. The results are based only on mothers' self-reports. A more robust research setting might include, for example, objective testing of infant motor and language skills and video- or audio-based data from mother-infant dyadic interactions. The mothers' own childhood abuse was based on retrospective reporting, which is hampered by memory biases, emotional upsets, and unwillingness to report negative issues about parents. Research has shown low agreement between prospective archive-documented and retrospective self-reported accounts of childhood maltreatment, suggesting that remembering maltreatment creates a higher mental health risk than the maltreatment itself (Newbury et al. 2018).

Concerning cultural sensitivity, our assessment of mother-infant dyadic interaction is based on emotional availability (Biringen et al. 2002) and attachment (Bowlby 1969) theories that are considered to reflect the aims, values, and practices of child rearing in individualistic societies (Keller 2013). Emotional availability, closeness, or sensitivity constitute a parenting strategy that supports a child's emotional expression and individuality (Keller and Otto 2009). Further studies are needed to better understand the cultural and sociopolitical salience of diverse parenting beliefs and dyadic interactions, such as by using long-term child developmental outcomes as criteria. Also, more research is necessary to learn about the degree of universality and culture-bounding in early rearing practices and dyadic interaction patterns especially in conflict and war areas. Our study did not have information about fathers or other caregivers, such as grandparents, although their role is important both in the infant's development and maternal wellbeing. This is a particular deficit, as extended families are common in Palestine.

Further shortcomings relate to the poor internal consistency of distant and negative dyadic mother-infant interactions, a non-significant loading of the sleeping arrangement item on the ethnotheories latent variable, and low $\beta$-values in some measurement models of parenting beliefs. These deficits may be indicative of the insensitivity of the applied research methods to Palestinian culture, as they do not catch the core significance of dyadic early phenomena in war conditions and the unique cultural setting. This therefore warrants caution in the interpretation of the results. Although the applied measurements were piloted for the current study, it would be advisable for future studies to put more emphasis on modifying the parenting beliefs and dyadic interaction concepts and items to ensure their validity in the specific context. A qualitative emic approach, where mothers, fathers, and other caregivers are directly asked about their parenting values, beliefs and caregiving practices could be useful for developing better and more valid research methods. 
All measures, except traumatic war events, were developed in different contexts and might thus not be the most suitable for Palestinians in the Gaza Strip. For instance, maternal mental health in pregnancy was measured using depression and anxiety scales developed in Western contexts and may not adequately capture relevant symptoms or subjective experiences in an ancient Middle Eastern culture or in unsafe military and political conditions (Kuittinen et al. 2017). It could be that other types of manifestation of mental distress are characteristic to Middle Eastern traditions or war conditions and are thus more relevant to parenting beliefs. Research shows that values, such as justice, human rights, dignity, and self-determination that are derived from the political-military situation contribute importantly to lay definitions of quality of life among Palestinians (Barber et al. 2016). It could be pivotal to identify Palestinians' own interpretations and cultural codes of both war events and childhood emotional and physical abuse, as well as parenting beliefs.

\section{Implications for Clinical Practice and Policy}

The current study indicates that mothers' prenatal mental health problems and earlier childhood trauma experiences impose a risk for the early mother-infant interaction in war conditions. Understandably, the very stressful and lifeendangering living conditions pose a strain on mothers' mental health and their ability to care for and protect their infants. International and non-governmental organizations should provide also psychosocial help in addition to material support. In cooperation with local health care it would be important to screen expectant mothers for childhood abuse experiences and mental health symptoms and target infant- and interaction-focused interventions for them. In order to prevent the traumatic experiences from passing onto the next generation, the mental health interventions should start already in the prenatal period, continue into support infant development, and enhance culturally adaptive practices. Culturally unique parenting beliefs are valuable source of strength, support and meaningfulness in war conditions. Thus, the interventions should be tailored to fit the cultural codes and to respect mothers' roles as caregivers to extended families and draw strengths from cultural variation in parenting values and practices. Optimally, interventions should also involve other caregivers in the same household, such as grand-parents, siblings and other relatives.

Besides interventions, alleviating the families' burden by any other mean in war conditions could be beneficial for the mothers' mental health and caregiving. For example, the often very large families would likely benefit from practical help with housekeeping and child care tasks, an easy access to basic supplies (electricity, clean water, food, sanitation, medication etc.), basic health services, and family planning.
The international and non-governmental organizations are valuable in combining practical help and resources with promoting mental health and infant wellbeing in ways that enhance culturally apt parenting.

Acknowledgements This study was supported by grants from the Academy of Finland (11232276) and the Finnish Cultural Foundation.

Author Contributions S.L.K.: designed the study, assisted with the data analyses, and wrote the paper. R.L.P.: analyzed the data and wrote part of the results and the paper. S.I.: collaborated with the design and writing of the study. S.Y.D. and S.R.Q. executed the study and collaborated in the writing and editing of the final paper.

\section{Compliance with Ethical Standards}

Conflict of Interest The authors declare that they have no conflict of interest.

Ethical Approval Ethical Board of The Palestinian Ministry of Health.

Informed Consent Participating mothers undersigned informed consent. The fieldwork and data registration were conducted in accordance with the 1964 Helsinki declaration and its later amendments and with to the APA ethical recommendations.

Publisher's note Springer Nature remains neutral with regard to jurisdictional claims in published maps and institutional affiliations.

Open Access This article is licensed under a Creative Commons Attribution 4.0 International License, which permits use, sharing, adaptation, distribution and reproduction in any medium or format, as long as you give appropriate credit to the original author(s) and the source, provide a link to the Creative Commons license, and indicate if changes were made. The images or other third party material in this article are included in the article's Creative Commons license, unless indicated otherwise in a credit line to the material. If material is not included in the article's Creative Commons license and your intended use is not permitted by statutory regulation or exceeds the permitted use, you will need to obtain permission directly from the copyright holder. To view a copy of this license, visit http://creativecommons. org/licenses/by/4.0/.

\section{References}

Baherie, A. (2013). Bayley sensory motor skills. Cairo: Elinhada Egyptian Library (In Arabic).

Barber, B. K., McNeely, C. A., El Sarraj, E., Daher, M., Giacaman, R., Arafat, C., \& Abu Mallouh, M. (2016). Mental suffering in protracted political conflict: feeling broken or destroyed. PLOS ONE, 11(5), e0156216. https://doi.org/10.1371/journal.pone.0156216.

Barber, B. K., Stolz, H. E., \& Olsen, J. A. (2005). Parental support, psychological control, and behavioral control: assessing relevance across time, culture, and method. Monographs of Society to Research in Child Development, 70(4), 1-137. https://doi.org/10. 1111/j.1540-5834.2005.00365.x.

Belsky, J. (2008). War, trauma and children's development: observations from a modern evolutionary perspective. International Journal of Behavioral Development, 32(4), 260-271. https://doi. org/10.1177/0165025408090969. 
Biringen, Z., Vliegen, N., Bijttebier, P., \& Cluckers, G. (2002). The emotional availability self-report. http://www.emotionalavaila bility.com

Bornstein, M. H., \& Cote, L. R. (2004). Mothers' parenting cognitions in cultures of origin, acculturating cultures, and cultures of destination. Child development, 75(1), 221-235. https://doi.org/10. 1111/j.1467-8624.2004.00665.x.

Bowlby, J. (1969). Attachment and loss: Volume I. Attachement. London: The Tavistock Institute of Human Relations.

Bravo, I., \& Noya, M. (2014). Culture in prenatal development: parental attitudes, availability of care, expectations, values, and nutrition. Child \& Youth Care Forum, 43(4), 521-538. https:// doi.org/10.1007/s10566-014-9251-4.

Brewer, M. B., \& Chen, Y. R. (2007). Where (who) are collectives in collectivism? Toward conceptual clarification of individualism and collectivism. Psychological Review, 114(1), 133-149. https:// doi.org/10.1037/0033-295X.114.1.133.

Cox, J. L., Holden, J. M., \& Sagovsky, R. (1987). Detection of postnatal depression: development of the 10-item Edinburgh Postnatal Depression Scale. The British Journal of Psychiatry, 150(6), 782-786.

El Azayem, G. A., \& Hedayat-Diba, Z. (1994). The psychological aspects of Islam: basic principles of Islam and their psychological corollary. The International Journal for the Psychology of Religion, 4(1), 41-50. https://doi.org/10.1207/s15327582ijpr0401_6.

Feldman, R., \& Masalha, S. (2007). The role of culture in moderating the links between early ecological risk and young children's adaptation. Developmental Psychopathology, 19, 1-21. https:// doi.org/10.1017/S0954579407070010.

Feldman, R., Masalha, S., \& Alony, D. (2006). Microregulatory patterns of family interactions: cultural pathways to toddlers' selfregulation. Journal of Family Psychology, 20, 614-623. https:// doi.org/10.1037/0893-3200.20.4.614.

Feldman, R., Vengrober, A., \& Ebstein, R. P. (2014). Affiliation buffers stress: cumulative genetic risk in oxytocin-vasopressin genes combines with early caregiving to predict PTSD in warexposed young children. Translational Psychiatry, 4, e370. https://doi.org/10.1038/tp.2014.6.

Field, T. (2011). Prenatal depression effects on early development: a review. Infant Behavior and Development, 34(1), 1-14. https:// doi.org/10.1016/j.infbeh.2010.09.008.

Glover, V. (2014). Maternal depression, anxiety and stress during pregnancy and child outcome; what needs to be done. Best Practice \& Research Clinical Obstetrics \& Gynaecology, 28(1), 25-35. https://doi.org/10.1016/j.bpobgyn.2013.08.017.

Hammami, R., \& Tamari, S. (2001). The second uprising: end or new beginning? Journal of Palestine Studies, 30(2), 5-25.

Hu, L. T., \& Bentler, P. M. (1999). Cutoff criteria for fit indexes in covariance structure analysis: Conventional criteria versus new alternatives. Structural Equation Modeling: A Multidisciplinary Journal, 6(1), 1-55.

Isosävi, S., Kuittinen, S., Quota, S., Diab, S. \& Punamäki, R.-L. (2020). Caregiving representations in war conditions: associations with maternal trauma, mental health, and mother-Infant Interaction. Infant Mental Health Journal, 1-18. https://doi.org/ 10.1002/imhj.21841

Kagitcibasi, C. (2005). Autonomy and relatedness in cultural context: implications for self and family. Journal of Cross-Cultural Psychology, 36(4), 403-422. https://doi.org/10.1177/ 0022022105275959 .

Kagitcibasi, C.(2012). Sociocultural change and integrative syntheses in human development: autonomous-related self and social-cognitive competence. Child Development Perspectives, 6 (1), 5-11. https://doi.org/10.1111/j.1750-8606.2011.00173.x.

Kaitz, M., Levy, M., Ebstein, R., Faraone, S. V., \& Mankuta, D. (2009). The intergenerational effects of trauma from terror: a real possibility. Infant Mental Health Journal, 30(2), 158-179. https:// doi.org/10.1002/imhj.20209.

Kartner, J., Keller, H., \& Yovsi, R. D. (2010). Mother-infant interaction during the first 3 months: the emergence of culture-specific contingency patterns. Child Development, 81(2), 540-554. https://doi.org/10.1111/j.1467-8624.2009.01414.x.

Keller, H. (2003). Socialization for competence: cultural models of infancy. Child Development, 69, 817-832. https://doi.org/10. $1159 / 000071937$.

Keller, H. (2007). Cultures of infancy. Mahwah, NJ, US: Lawrence Erlbaum Associates Publishers.

Keller, H. (2013). Attachment and culture. Journal of Cross-Cultural Psychology, 44(2), 175-194. https://doi.org/10.1177/ 0022022112472253.

Keller, H., Borke, J., Lamm, B., Lohaus, A., \& Yovsi, R. D. (2011). Developing patterns of parenting in two cultural communities. International Journal of Behavioral Development, 35, 233-245. https://doi.org/10.1177/0165025410380652.

Keller, H., Lamm, B., Abels, M., Yovsi, R., Borke, J., Jensen, H., \& Su, Y. (2006). Cultural models, socialization goals, and parenting ethnotheories: a multicultural analysis. Journal of Cross-Cultural Psychology, 37(2), 155-172. https://doi.org/10.1177/0022022105284494.

Keller, H., \& Otto, H. (2009). The cultural socialization of emotional regulation during infancy. Journal of Cross-Cultural Psychology, 40, 996-1011. https://doi.org/10.1177/0022022109348576.

Keller, H., Otto, H., Lamm, B., Yovsi, R. D., \& Kartner, J. (2008). The timing of verbal/vocal communications between mothers and their infants: a longitudinal cross-cultural comparison. Infant Behavavioral Development, 31(2), 217-226. https://doi.org/10. 1016/j.infbeh.2007.10.001.

Kopparthi, R., McDermott, C., Sheftel, D., Lenke, M. C., Getz, M., \& Frey, M. (1991). The Minnesota Child Development Inventory: validity and reliability for assessing development in infancy. Journal of Devevelopment and Behavior Pediatry, 2(4), 217-222.

Kuittinen, S., García Velázquez, R., Castaneda, A.E., Punamäki, R.L., Rask, S., \& Suvisaari, J. (2017). Construct validity of the HSCL25 and SCL-90-Somatization scales among Russian, Somali and Kurdish origin migrants in Finland. International Journal of Culture and Mental Health, 10, 1-18. https://doi.org/10.1080/ 17542863.2016.1244213.

Levin, J. S. (1991). The factor structure of the Pregnancy Anxiety Scale. Journal of Health and Social Behavior, 32, 368-381.

Levy, M. (2006). Maternity in the wake of terrorism: rebirth or retraumatization? Journal of Prenatal and Perinatal Psychology and Health, 20(3), 221-248.

Lyons-Ruth, K., Dutra, L., Schuder, M. R., \& Bianchi, I. (2006). From infant attachment disorganization to adult dissociation: Relational adaptations ortraumatic experiences? Psychiatric Clinics, 29(1), 63-86. https://doi.org/10.1016/j.psc.2005.10.011.

Lyytinen, P., Ahonen, T., Eklund, K., \& Lyytinen, H. (2000). Assessment of vocal and motoric development in infancy. Jyväskylä: Niilo Mäki Instituutti. in Finnish.

MacKinnon, D. P., Lockwood, C. M., \& Williams, J. (2004). Confidence limits for the indirect effect Distribution of the product and resampling methods. Multivariate Behavioral Research, 39 (1), 99-128. https://doi.org/10.1207/s15327906mbr3901_4.

Marey-Sarwan, I., Keller, H., \& Otto, H. (2016). Stay close to me: stranger anxiety and maternal beliefs about children's socioemotional development among bedouins in the unrecognized villages in the Naqab. Journal of Cross-Cultural Psychology, 47 (3), 319-332. https://doi.org/10.1177/0022022115619231.

Marsella, A. J.(2010). Ethnocultural aspects of PTSD: an overview of concepts, issues, and treatments. Traumatology, 16(4), 17-26. https://doi.org/10.1177/1534765610388062.

Marsella, A. J., \& Yamada, A. (2000). Culture and mental health: An introduction and overview of foundations, concepts, and issues. 
In I. Cuellar \& F. Paniagua (Eds.), Handbook of multicultural mental health (pp. 3-24). New York: Academic Press.

McMillan, K. A., \& Asmundson, G. J. (2016). PTSD, social anxiety disorder, and trauma: an examination of the influence of trauma type on comorbidity using a nationally representative sample. Psychiatry Research, 246, 561-567. https://doi.org/10.1016/j. psychres.2016.10.036.

Mollica, R. F., Caspi-Yavin, Y., Bollini, P., Truong, T., Tor, S., \& Lavelle, J. (1992). The Harvard Trauma Questionnaire. Validating a cross-cultural instrument for measuring torture, trauma, and post traumatic stress disorder in Indochinese refugees. Journal of Nervous and Mental Disorders, 180, 111-116. https://doi.org/10. 1097/00005053-199202000-00008.

Newbury, J. B., Arseneault, L., Moffitt, T. E., Caspi, A., Danese, A., Baldwin, J. R., \& Fisher, H. L. (2018). Measuring childhood maltreatment to predict early-adult psychopathology: comparison of prospective informant-reports and retrospective self-reports. Journal of Psychiatric Research, 96, 57-64. https://doi.org/10. 1016/j.jpsychires.2017.09.020.

Palosaari, E., Punamäki, R.-L., Qouta, S., \& Diab, M. (2013). Intergenerational effects of war trauma among Palestinian families mediated via psychological maltreatment. Child Abuse \& Neglect, 37(11), 955-968. https://doi.org/10.1016/j.chiabu.2013.04.006.

Punamäki, R.L. Isosävi, S., Qouta, S.R., Kuittinen, S., \& Diab, S.Y. (2017). War trauma and maternal-fetal attachment predicting maternal mental health, infant development and dyadic interaction in Palestinian families. Attachment and Human Development, https://doi.org/10.1080/14616734.2017.1330833.

Punamäki, R. L., Komproe, I., Qouta, S., El-Masri, M., \& de Jong, J. T. (2005). The deterioration and mobilization effects of trauma on social support: childhood maltreatment and adulthood military violence in a Palestinian community sample. Child Abuse \& Neglect, 29(4), 351-373. https://doi.org/10.1016/j.chiabu.2004. 10.011 .

Punamäki, R. L. (2014). Mental health and development among children living in violent conditions: underlying mechanisms for promoting peace. In P. Britto, J. F. Leckman, C. Panter-Brick \& R. Salah (Eds.), Pathways to peace: The transformative power of children and families. Strüngmann Forum Reports, vol 15, J Lupp, series ed., Cambridge, MA: MIT Press.

Punamäki, R. L., Qouta, S., \& Peltonen, K. (2018). Family systems approach to attachment relations, war trauma and mental health among Palestinian children and parents. European Journal of Psychotraumatology, 8, 1439649. https://doi.org/10.1080/ 20008198.2018.1439649.

Qouta, S., Punamaki, R. L., \& El Sarraj, E. (2008). Child development and family mental health in war and military violence: the Palestinian experience. International Journal of Behavioral Development, 32(4), 310-321. https://doi.org/10.1177/0165025408090973.

Saile, R., Ertl, V., Neuner, F., \& Catani, C. (2014). Does war contribute to family violence against children? Findings from a twogenerational multi-informant study in Northern Uganda. Child Abuse \& Neglect, 38(1), 135-146. https://doi.org/10.1016/j.chia bu.2013.10.007.

Savage, L. É., Tarabulsy, G. M., Pearson, J., Collin-Vézina, D., \& Gagné, L. M. (2019). Maternal history of childhood maltreatment and later parenting behavior: a meta-analysis. Development and Psychopathology, 31(1), 9-21. https://doi.org/10.1017/S0954579418001542.
Save the Children International (2018). War on children. Time to end violations against children in armed conflict. https://www.sa vethechildren.net/sites/default/files/waronchildren/. Retriewed 24.02.2020.

Schechter, D. S., \& Willheim, E. (2009). When parenting becomes unthinkable: intervening with traumatized parents and their toddlers. Journal of the American Academy of Child \& Adolescent Psychiatry, 48(3), 249-253.

Singer, P. W. (2006). Children at war. Berkeley: University of California Press.

Slade, A. (2005). Parental reflective function: An introduction. Attachment \& Human Development, 7(3), 269-281. https://doi. org/10.1080/14616730500245906.

Stern, D. N. (1998). The motherhood constellation: A unified view of parent-infant psychotherapy. London: Karnac Books.

Super, C. M., \& Harkness, S. (2002). Culture structures the environment for development. Human Development, 45, 270-274.

Taylor, S. E., Klein, L. C., Lewis, B. P., Gruenewald, T. L., Gurung, R. A., \& Updegraff, J. A. (2000). Biobehavioral responses to stress in females: tend-and-befriend, not fight-or-flight. Psychological Review, 107(3), 411-429. https://doi.org/10.1037/0033295X.107.3.411.

Triandis, H. C. (2000). Cultural syndromes and subjective well-being. In E. F. Diener \& E. M. Suh (Eds.), Subjective well-being across cultures (pp. 87-112). Cambridge, MA: MIT Press.

UN-Human Rights Council. (2015). The United Nations Independent Commission of Inquiry on the 2014 Gaza conflict. http://www. ohchr.org/EN/HRBodies/HRC/CoIGaza/Conflict/Pages/ ReportCoIGaza.aspx.

UN-OCHA (2014). Occupied Palestinian Territory. Gaza Emergency Situation Report. 4 September 2014. United Nations Office for the Coordination of Humanitarian Affairs, OCHA, https://www. ochaopt.org/documents/ocha_opt_sitrep_04_09_2014.pdf, retrieved 24.02.2020.

UN-OCHA (2017). The humanitarian impact of the blockade. https://www.ochaopt.org/content/gaza-strip-humanitarian-impactblockade, retrieved 24.02.2020.

Vaillancourt, K., Pawlby, S., \& Fearon, R. P. (2017). History of childhood abuse and mother-infant interaction: a systematic review of observational studies. Infant Mental Health Journal, 38 (2), 226-248. https://doi.org/10.1002/imhj.2163.

Van Ee, E., Kleber, R. J., \& Mooren, T. T. (2012). War trauma lingers on: associations between maternal posttraumatic stress disorder, parent-child interaction, and child development. Infant Mental Health Journal, 33(5), 459-468. https://doi.org/10.1002/imhj. 21324.

Vliegen, N., Luyten, P., \& Biringen, Z. (2009). A multimethod perspective on emotional availability in the postpartum period. Parenting, Science and Practice, 9(3-4), 228-243. https://doi.org/ 10.1080/15295190902844514.

Vohringer, I. A., Poloczek, S., Graf, F., Lamm, B., Teiser, J., Fassbender, I., \& Knopf, M. (2015). Is perceptual priming affected by culture? A study with German middle-class and Cameroonian Nso farmer children. Journal of Genetic Psychology, 176(3-4), 156-170. https://doi.org/10.1080/00221325.2015.1023178.

World Bank (2015). World Bank Report: economic monitoring report to the ad hoc liaison committee. http://documents.worldbank.org/ curated/en/563181468182960504/pdf/96601. 